LAWRENCE LIVERMORE NAT IO N A L LABORATORY

\title{
A Plutonium Ceramic Target for MASHA
}

P. A. Wilk, D. A. Shaughnessy, K. J. Moody, J. M.

Kenneally, J. F. Wild, M. A. Stoyer, J. B. Patin, R. W. Lougheed, B. B. Ebbinghaus, R. L. Landingham, Y. T. Oganessian, A. V. Yeremin, S. N. Dmitriev

July 12,2004

International Symposium on Exotic Nuclei

Peterhof, Russia

July 5, 2004 through July 12, 2004 
This document was prepared as an account of work sponsored by an agency of the United States Government. Neither the United States Government nor the University of California nor any of their employees, makes any warranty, express or implied, or assumes any legal liability or responsibility for the accuracy, completeness, or usefulness of any information, apparatus, product, or process disclosed, or represents that its use would not infringe privately owned rights. Reference herein to any specific commercial product, process, or service by trade name, trademark, manufacturer, or otherwise, does not necessarily constitute or imply its endorsement, recommendation, or favoring by the United States Government or the University of California. The views and opinions of authors expressed herein do not necessarily state or reflect those of the United States Government or the University of California, and shall not be used for advertising or product endorsement purposes. 


\title{
A PLUTONIUM CERAMIC TARGET FOR MASHA
}

\author{
P.A. WILK, D.A. SHAUGHNESSY, K.J. MOODY, J.M. KENNEALLY, J.F. WILD, \\ M.A. STOYER, J.B. PATIN, R.W. LOUGHEED, B.B. EBBINGHAUS, AND R.L. \\ LANDINGHAM \\ Chemistry and Materials Science, Lawrence Livermore National Laboratory, Livermore, \\ CA 94550, USA
}

\author{
YU.TS. OGANESSIAN, A.V. YEREMIN, S.N. DMITRIEV
}

Flerov Laboratory of Nuclear Reactions, Joint Institute for Nuclear Research, Dubna, Russia

We are currently developing a plutonium ceramic target for the MASHA mass separator. The MASHA separator will use a thick plutonium ceramic target capable of tolerating temperatures up to $2000^{\circ} \mathrm{C}$. Promising candidates for the target include oxides and carbides, although more research into their thermodynamic properties will be required. Reaction products will diffuse out of the target into an ion source, where they will then be transported through the separator to a position-sensitive focal-plane detector array. Experiments on MASHA will allow us to make measurements that will cement our identification of element 114 and provide for future experiments where the chemical properties of the heaviest elements are studied.

\section{Introduction}

\subsection{The MASHA Separator}

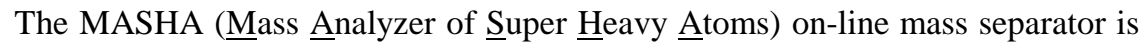
currently under development at the Flerov Laboratory of Nuclear Reactions at JINR. This separator is expected to have a number of improvements over existing recoil separators, and will provide at least a ten-fold increase in the production and detection rate for element 114. It will allow unambiguous mass identification of super heavy nuclei with a mass resolution better than $1 \mathrm{amu}$ [1].

One proposal for the MASHA target is a thick, ceramic target (uranium or plutonium) heated to a temperature of approximately $2000^{\circ} \mathrm{C}$. The advantage of this type of target over thin targets is that the ceramic will see a large range of beam energies so more of the excitation function will be sampled. The effective width of the excitation function is about $25 \mathrm{MeV}$ with a thick target compared to only $3 \mathrm{MeV}$ with a traditional thin target.

\footnotetext{
* Corresponding author email shaughnessy2@1lnl.gov.
} 
The target will be a combination actinide target and ion source of the CERN-ISOLDE type [2,3]. Reaction products will diffuse out of the heated, porous target and drift to an ion source where they will be ionized and injected into the separator. After traveling through the separator, the products will impinge on a position-sensitive focal-plane detector array for mass measurement. Initial tests will use uranium ceramics, but ultimately, element 114 experiments will be performed using ceramics made from ${ }^{244} \mathrm{Pu}$ (about $15 \%$ of the world's supply) bombarded with a ${ }^{48} \mathrm{Ca}$ beam.

\subsection{Target Requirements and Preparation}

The plutonium target for MASHA must meet several requirements. It must be physically stable and able to withstand a temperature of $2000{ }^{\circ} \mathrm{C}$ without melting or thermally expanding. The target must be stable over a large temperature range without undergoing phase transitions that would result in an unstable compound or a compound with a much lower melting point. The plutonium vapor pressure cannot be so high as to contaminate the ion source or separator, and finally, the diffusion rate of reaction products from the target must be fast enough to allow measurement of short-lived products.

The kind of material that would best meet these requirements appears to be a binary compound of uranium or plutonium, namely a carbide or oxide. In order to produce these compounds, they must be heated to temperatures on the order of $1800{ }^{\circ} \mathrm{C}$. In addition, the use of large quantities of plutonium requires the use of a glove box for safety considerations. A custom made furnace (Micropyretics Heaters International) has been designed for this project that reaches these temperatures without emitting too much heat externally, which could pose a safety hazard inside of a glove box. The furnace is also small enough to fit inside the standard-sized glove boxes we currently have at LLNL.

\section{Relevant Plutonium Compounds}

Of the known binary plutonium compounds, there are several that meet the first requirement of a melting point greater than $2000{ }^{\circ} \mathrm{C}$. These include plutonium carbides, nitrides, sulfides, and oxides. In order to decide which compound is best suited for MASHA, the physical and thermodynamic properties, as well as the ease of preparation, of each compound must be considered.

Plutonium mononitride may be a promising candidate, but it is highly reactive with a variety of common reagents and is readily oxidized in air. It also decomposes before reaching its reported melting point of $2830{ }^{\circ} \mathrm{C}$ [4]. The other disadvantage of $\mathrm{PuN}$ is its large vaporization pressure [5]. Likewise, plutonium monosulfide is reported to have a melting point of $2350{ }^{\circ} \mathrm{C}$ [6], but it 
too has a large volatility and exhibits a high coefficient of thermal expansion [7]. More research on the plutonium-sulfur phase diagram would need to be done before ruling out plutonium sulfides completely.

The two most promising systems are plutonium carbides and oxides. The one disadvantage with the plutonium-carbon system is that the phase diagram shows a phase transition at $1600{ }^{\circ} \mathrm{C}$ where $\mathrm{Pu}_{2} \mathrm{C}_{3}$ transforms into $\mathrm{PuC}_{2}$, which is unstable at lower temperatures [5]. If the target is to have repeated use, this makes the carbide unattractive, since heating it to $2000{ }^{\circ} \mathrm{C}$ would create a compound that would be unstable once the temperature was lowered. Although plutonium carbides should not be ruled out at this time, more work needs to be done to investigate their thermodynamic properties.

More information is known about the plutonium oxides than any of the other binary compounds. $\mathrm{PuO}_{2}$ satisfies most of the target requirements and is coincidentally the easiest compound to prepare. It has the lowest vapor pressure at elevated temperatures $\left(6 \times 10^{-6}\right.$ atm at $2000{ }^{\circ} \mathrm{C}$ [8]) in addition to a high melting point $\left(2425^{\circ} \mathrm{C}[5]\right)$. One potential drawback is that $\mathrm{PuO}_{2}$ reacts with tantalum to form $\mathrm{Pu}_{2} \mathrm{O}_{3}$ (tantalum is currently proposed as the support material.) $\mathrm{Pu}_{2} \mathrm{O}_{3}$ has a comparable vapor pressure and melting point $\left(2080{ }^{\circ} \mathrm{C}[5]\right)$; the effect this transformation would have on the structural integrity of the target needs to be investigated furhter. Figure 1 shows the plutonium-oxygen phase diagram from Ref. [5].

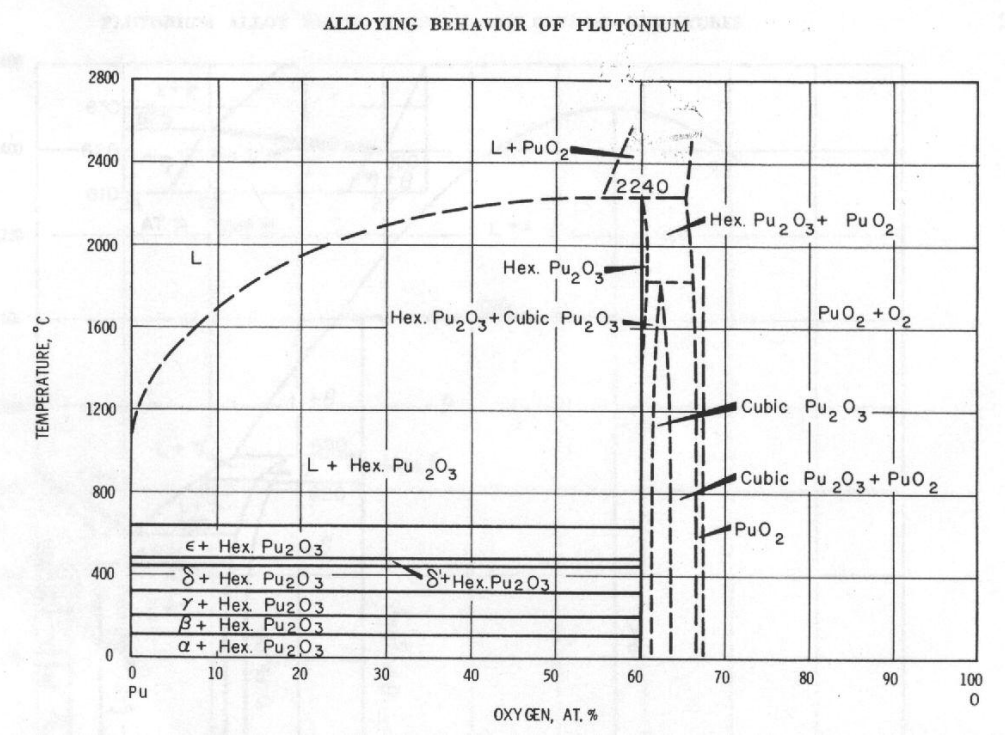

Figure 1. Plutonium-oxygen phase diagram (Ref. [5].) 


\section{Conclusions}

Candidates for the MASHA target are currently being prepared and characterized. On-line tests with MASHA will begin with uranium carbides, but subsequent irradiations with ${ }^{242} \mathrm{Pu}$ and ultimately ${ }^{244} \mathrm{Pu}$ will be performed. The plutonium oxides appear to be the best candidates for the ceramic target, although the carbides should not be ruled out. Once the target is prepared and tested, experiments designed to measure the mass of element 114 will begin.

\section{Acknowledgments}

This work was performed under the auspices of the U.S. Department of Energy by University of California, Lawrence Livermore National Laboratory under Contract W-7405-Eng-48.

\section{References}

1. Yu. Ts. Oganessian et al., Nucl. Instrum. Meth. Phys. Res. B204, 606 (2003).

2. L. C. Carraz et al., Nucl. Instrum. Meth. 148, 217 (1978).

3. H. L. Ravn, Phys. Reports 54, 201 (1979).

4. J. M. Cleveland, The Chemistry of Plutonium (American Nuclear Society, LaGrange Park, IL, 1979), 653.

5. M. E. Kassner and D. E. Peterson, Editors, Phase Diagrams of Binary Actinide Alloys (ASM International, Materials Park, OH, 1995), 489.

6. O. L. Kruger and J. B. Moser, J. Inorg. Nucl. Chem. 28, 825 (1966).

7. J. H. Handwerk, O. L. Kruger, and J. B. Moser in Plutonium 1965, A. E. Kay and M. B. Waldron, Editors (Chapman and Hall, London, 1965), 739750.

8. B. B. Ebbinghaus, personal communication (2003). 